\title{
A COMPARISON OF THE ELEVATED TEMPERATURE FATIGUE CRACK GROWTH OF THREE ALLOY STEELS
}

\author{
M.B. Cortie \\ Council for Mineral Technology, Private Bag X3015, Randburg 2125, South Africa
}

\section{G.G. Garrett}

National Institute for Materials Research, Council for Scientific and Industrial Research, P.O. Box 395, Pretoria 0001, South Africa

\begin{abstract}
Fatigue crack growth rates for a triangular loading wave form with a frequency of $1 \mathrm{~Hz}$ and an $R$-ratio of 0.1 were determined for the steel alloys Fe- $1 \% \mathrm{Cr}-0.5 \% \mathrm{Mo}$ and $\mathrm{Fe}-1.5 \% \mathrm{Mn}-0.8 \% \mathrm{Ni}-0.5 \% \mathrm{Mo}$ (SA508) at $450^{\circ} \mathrm{C}$ and for $\mathrm{Fe}-$ $1 \% \mathrm{Cr}-0.5 \% \mathrm{Mo}$ and $\mathrm{Fe}-0.5 \% \mathrm{Cr}-0.5 \% \mathrm{Mo}-0.25 \% \mathrm{~V}$ at $550^{\circ} \mathrm{C}$. Statistical methods were used in order to determine whether any of the alloys possessed significantly different fatigue crack growth resistance but it was found that the crack growth rates over the range of alternating stress intensities applied were very similar for each pair of alloys tested. It was also found that use of the Paris Law to describe fatigue crack growth rates would have led to an erroneous conclusion in this regard. A sigmoidal descriptive model for fatigue crack growth is proposed which, with the widespread availability of microcomputers, is not much more difficult to apply than the Paris Law, but which is able to describe the data far better.
\end{abstract}

$1 \mathrm{Cr}-0.5 \mathrm{Mo}, 1 / 2 \mathrm{Cr}-1 / 2 \mathrm{Mo}-1 / 4 \mathrm{~V}$, SA508, elevated temperature fatigue, effect of alloy composition, sigmoidal model, crack propagation, statistics, scatter

\section{INTRODUCTION}

The experimental work described in this paper deals with the fatigue crack growth rates of three alloy steels, namely Fe$1 \% \mathrm{Cr}-0.5 \% \mathrm{Mo}$, Fe- $0.5 \% \mathrm{Cr}-0.5 \% \mathrm{Mo}-0.25 \% \mathrm{~V}$, and $\mathrm{Fe}-1.5 \% \mathrm{Mn}-0.8 \% \mathrm{Ni}-0.5 \% \mathrm{Mo}$ (SA508). The first two alloys are widely used for elevated temperature applications in chemical plant and thermal power generation, whereas SA508 is specifically intended for service in nuclear pressure vessel components at about $300^{\circ} \mathrm{C}$. SA508 also differs significantly in a metallurgical sense from the first two alloys since it does not derive its strengthening from chromium additions but rather from increased manganese and nickel. In addition, it is normally used in a tempered bainitic condition whereas the first two alloys are normally applied with the carbide phases distributed in a nominally pearlitic fashion.

This paper addresses the question of whether or not there are statistically significant variations in the Stage II crack propagation resistance at elevated temperature between these three steel alloys.

Secondly, this paper also presents methods by which the statistical scatter in fatigue crack propagation data can be modeled and accounted for. This information may be of value to other investigators of fatigue crack propagation. In all cases the units of measurement used are $\mathrm{m} /$ cycle for $\mathrm{d} a / \mathrm{d} N$ and $\mathrm{MPa} \cdot \mathrm{m}^{0.5}$ for stress intensity.

\section{EFFECT OF MICROSTRUCTURE AND COMPOSITION}

It is now widely accepted that room temperature Stage II fatigue crack growth is generally not very sensitive to either microstructure or alloy composition and that careful work is required to reveal any small differences between materials that might exist[1,2]. Fatigue crack growth rates near the region of the threshold alternating stress, $\Delta \mathrm{K}_{\mathrm{th}}$, are, on the other hand, quite sensitive to microstructural variations[1,2].

It is known, however, that there is a small difference between ferrite-pearlite materials and other, more homogeneous ferrous alloys[3,4]. This is said[3] to arise from the fact that pearlite colonies tend to cause branching of the fatigue crack front. The branching of cracks leads to an effective reduction of crack tip strain (and stress) and hence a reduced driving force for crack growth. This effect is generally small and is not normally of practical importance. Benson and 
Edmonds[5], for example, examined the effect of microstructure on room temperature fatigue crack propagation in Fe$0.5 \% \mathrm{Cr}-0.5 \% \mathrm{Mo}-0.25 \% \mathrm{~V}$. They found that, above about $20 \mathrm{MPa} . \mathrm{m}^{0.5}$, there was little or no difference in crack growth rates of large-grained ferritic structures and fine-grained bainitic and tempered martensitic structures. However, near the fatigue threshold, there was a significant difference with the fine-grained material exhibiting faster growth rates. Even greater variations of fatigue crack growth rate with microstructure are recorded in the dual phase steels[6,7]. In these materials, which usually consist of a mixture of ferrite and martensite, the microstructure effects both threshold and Stage II crack propagation. In particular, fatigue crack propagation was more rapid when the ferrite phase was encapsulated by the martensite, compared to the reverse condition[7]. In this case it was believed that the martensite offered a barrier at which cracks in the ferrite phase were arrested.

While the variation of room temperature Stage II fatigue crack propagation with microstructure is generally small, the variation with composition, for similar microstructures, is almost negligible. Poon et al.[8], for example, studied fatigue crack propagation in a range of $\mathrm{Cr}-\mathrm{Mo}-\mathrm{V}$ steels at room temperature and claimed that there was "essentially no difference" between them. Chromium contents varied from $0.75 \%$ to $2.0 \%$, molybdenum from $0.15 \%$ to $1.5 \%$ and vanadium from $0 \%$ to $0.3 \%$. Ishii et al.[9] have examined the effect on fatigue crack propagation in ferrite of twelve substitutional solute elements. While some of the elements, especially silicon and nickel, had a strong effect on the smooth specimen ' $S-N$ ' fatigue resistance of the alloys, the effect on fatigue crack propagation was far smaller. Cobalt, copper, nickel, niobium and silicon in amounts of three or four percent did seem to exert a measurably beneficial influence on fatigue crack propagation in ferrite at an alternating stress intensity of $20 \mathrm{MPa} \cdot \mathrm{m}^{0.5}$. The effect of manganese, vanadium, titanium and carbon at this stress intensity was negligible. In most cases the beneficial effect of the alloying element addition became more noticeable at stress intensities below $20 \mathrm{MPa} \cdot \mathrm{m}^{0.5}$. These results should not be generalized and applied to alloy steels however, as the alloys of Ishii et al. had extremely low carbon contents. Chromium, titanium and vanadium, in particular, form carbides in alloy steel and the presence and morphology of these would also influence fatigue crack propagation.

A characteristic common to several of the studies discussed above is that the authors have not applied any statisticallybased technique in order to determine whether the various fatigue crack data sets are genuinely different.

Surprisingly, there are relatively few reported studies that have examined in detail the influence of composition or microstructure on fatigue crack growth in ferrous materials at elevated temperatures. However, while comparative elevated temperature fatigue crack propagation work is rather scarce, there have been several 'smooth specimen' studies which have compared various materials[10-12]. In these cases both alloy composition and microstructure have been shown to have a strong effect on crack initiation and, hence, specimen life. In general the studies show that the improved fatigue limits are positively correlated with higher tensile and creep strengths, and improved oxidation resistance.

In cases where the basic mechanical fatigue crack growth mechanism operates in conjunction with a time-dependent mechanism such as corrosion, oxidation or creep, it might be expected that the fatigue crack growth rate would show an increased sensitivity to alloy composition and microstructure[13]. This follows from the fact that the time dependent processes are sensitive to various aspects of alloy composition or microstructure. Since time-dependent mechanisms, especially creep and oxidation, become increasingly important at elevated temperatures, it might be expected that the composition and microstructure of alloy steels would play an increasingly important role at elevated temperature.

\section{EXPERIMENTAL DETAILS}

In all cases the fatigue conditions were standardized to a $1 \mathrm{~Hz}$ triangular wave with an $R$-ratio of 0.1 . All testing was conducted in air on an ESH servohydraulic test system. Several tests were run for each alloy, some using a computercontrolled electrical potential method of crack length measurement and others using direct beachmarking under the control of a computer program developed explicitly for that purpose. It was found that the beachmarking method was more accurate although it yielded rather fewer data points. The potential drop technique was susceptible to electrical and thermal noise but did yield data showing similar trends to the beachmarking method.

In the case of the potential drop testing, the direct calculation method outlined by Schwalbe and Hellman[14] was employed. The final crack length was measured after breaking open the specimen and a small correction applied to the theoretical crack length calculated from the Johnson equation.

In the case of the beachmarking, five crack length measurements were made for each boundary and the results processed in a spreadsheet computer program to yield the mean and standard deviation for the $\Delta K$ and $\mathrm{d} a / \mathrm{d} N$ associated with each block of crack growth. Different methods of producing clearly visible beachmarks were attempted, including changes in frequency or waveform, and it was found that any method which produced significantly reduced rates of crack growth compared to the main block was suitable. Further details of the techniques used are available 
elsewhere[15].

\section{MECHANISM OF CRACK ADVANCE}

Figure 1 shows a typical striated fatigue surface for SA508 tested at $450^{\circ} \mathrm{C}$. At this point $\Delta K$ was about $32 \mathrm{MPa}^{0.5}$ and the rate of crack propagation was close to $2 \times 10^{-7} \mathrm{~m} /$ cycle.

$1 \% \mathrm{Cr}-0.5 \%$ Mo also showed striated crack surfaces and Figure 2 shows a typical example. Here $\Delta K$ was about 33 MPa.m $\mathrm{m}^{0.5}$ and $\mathrm{d} a / \mathrm{d} N$ about $3 \times 10^{-7} \mathrm{~m} /$ cycle.

Fatigue at $550^{\circ} \mathrm{C}$ and $1 \mathrm{~Hz}$ for $1 \% \mathrm{Cr}-0.5 \% \mathrm{Mo}$ and $0.5 \% \mathrm{Cr}-0.5 \% \mathrm{Mo}-0.25 \% \mathrm{~V}$ was also characterized by striation formation. Figures 3 shows geometrically regular fatigue striations near the crack tip of a $1 \% \mathrm{Cr}-0.5 \% \mathrm{Mo}$ specimen tested at $550^{\circ} \mathrm{C}$. Notice the eroding effect of oxidation. The brittle cleavage visible at the top of the photograph was produced by breaking open the cracked specimen after cooling to $-196^{\circ} \mathrm{C}$.

Figure 4 shows a region of rather poorly defined striations on $0.5 \% \mathrm{Cr}-0.5 \% \mathrm{Mo}-0.25 \% \mathrm{~V}$ fatigued at $550^{\circ} \mathrm{C}$. The rate of crack growth at this point was approximately $5 \times 10^{-7} \mathrm{~m} /$ cycle and $\Delta K$ was about $31 \mathrm{MPa} \cdot \mathrm{m}^{0.5}$.

The scanning electron microscope fractography of the fatigue crack surfaces revealed that the cracks propagated by means of the classic striation-forming alternating blunting/ resharpening mechanism. No sign of creep cavitation was observed on these crack surfaces.

\section{STATISTICAL SCATTER IN FATIGUE CRACK GROWTH}

\section{General}

It is widely known that there is a considerable degree of scatter in fatigue crack growth rates, even for nominally identical specimens. Much of this variation arises from experimental imperfections, primarily from the fact that, as yet, no direct, convenient non-destructive method is available to measure the length of a crack inside a specimen while it is growing. However, some of the variation arises from the material itself and represents the inherent variation for the particular material/specimen size combination.

The Paris 'Law' for fatigue crack growth[16],

$$
\begin{aligned}
& \mathrm{d} a \\
& --
\end{aligned}=C \cdot \Delta K^{\mathrm{m}}
$$

has often been usefully employed as a method for correlating and comparing fatigue crack growth rates. In particular, several workers have made use of the Paris Law as a convenient starting point from which to examine the intrinsic degree of scatter and variation in fatigue crack growth rates.

For example, the degree of inherent variation in the Paris coefficients used to characterize a material's Stage II crack propagation behaviour has been studied by Johnston[17] who concluded that the coefficient, ' $C$ ', in the Paris equation for either SA508 or SA533, tested in air at room temperature, has an inherent log normal distribution with a mean $\ln (C)$ of -29.31 and a standard deviation of 0.24 . Since a $95 \%$ confidence interval for $C$ will be very nearly given by two standard deviations on either side of the mean, it is possible to calculate that $C$ will have at least a $95 \%$ C.I. of, in this case and for units of $\mathrm{m} /$ cycle and MPa.m ${ }^{0.5}$, from $1.15 \times 10^{-13}$ to $3.02 \times 10^{-13}$.

In his work Johnston made use of an empirical correlation between $C$ and $m$ which has been noticed by several workers[18-21]. By substituting the two extremes of the $95 \%$ confidence interval for $C$ back into this $C-m$ relationship, a rather conservative estimate for $m$ can be obtained, in this case, 2.93 to 3.07 .

Ostergaard and Hillberry[22] have also been interested in the inherent scatter in the Paris parameters. They refer to 68 identical tests performed by Virkler with the express purpose of addressing this issue. The ' $m$ ' values obtained in these tests ranged from 1.90 to 2.73 with the distribution appearing to be approximately normal. 
A further example of the scatter in ' $C$ ' and ' $m$ ' is given in the important paper by Clarke and Hudak[23] in which the foundation for the ASTM fatigue crack growth specification[24] was laid. In this case the mean value of ' $m$ ' for a ' $10 \mathrm{Ni}$ $8 \mathrm{Co}-\mathrm{Mo'}^{\prime}$ steel was 2.03 and the $95 \%$ C.I. for this parameter (calculated for the present work by taking two standard deviations on either side of the mean) was 1.55 to 2.51 . This particular paper includes the results of 78 individual tests conducted at different laboratories under different conditions and thus some of this scatter must, of course, be attributed to factors other than an inherent material property. Nevertheless, Clark and Hudak concluded that there was not any statistically large difference between the results yielded by the various testing methods or laboratories, and that all 78 values of $m$ were valid.

It is thus clear that, since there is a degree of inherent variation in fatigue crack growth rates, a single test conducted under a particular set of conditions does not provide a statistically useful indication of the rate of fatigue crack growth. In order to obtain more meaningful information it is necessary, in the case of fatigue crack growth at least, to either run more than one test at a given condition or vary the conditions systematically in small increments while performing a single test at each condition. In either event it is obvious that some of the published work on fatigue crack propagation is deficient in the sense that insufficient data was collected to provide a meaningful answer. Similar considerations apply to work in which regression lines have been fitted to a handful of data points and the numerical result provided without either the original data points or the statistical relevance of the 'equation' being published.

In order to objectively assess the $\mathrm{d} a / \mathrm{d} N$ data pertaining to different conditions or materials a statistical technique is necessary. Two methods have been employed here. The first relies on the use of the Paris Law to describe the data and is somewhat simpler from a computational point of view. The data obtained at elevated temperatures are not markedly linear however and are not well described by a log-linear model. The second method described here consists of fitting a descriptive sigmoidal-shaped model to each of the data sets by means of non-linear least-square optimization and constructing approximate confidence intervals for each of the curves.

\section{Use of the Paris Law}

Although it is frequently desirable to compare two nominally similar sets of ordered pairs in order to determine whether they are different or not, there is no simple statistical test that addresses this problem. It is possible, however, to construct confidence intervals for an equation applied to a data set[25]. These confidence intervals are approximately given by vertical displacements from the fitted curves which depend on the standard error of estimate of $y$ on $x\left(S_{\mathrm{y} / \mathrm{x}}\right)$ for the data. In the case of straight lines, it is possible to calculate $95 \%$ confidence intervals for the mean value of a data set relatively directly. Such intervals are not linear themselves, however, since there is naturally more uncertainty at the two ends of a collection of linear data than at their centre.

In the case of linear regression model $S_{\mathrm{y} / \mathrm{x}}$ is given by

$$
\left(S_{y / x}\right)^{2}=\frac{\sum\left(y_{i}\right)^{2}-a_{0} \cdot \sum y_{i}-a_{1} \cdot \sum x_{i} \cdot y_{i}}{(n-2)}
$$

where $a_{0}$ and $a_{1}$ are from the regression line $y=a_{0}+a_{1} . x$. Once this is known then $100(1-\dot{\tau} \%$ confidence intervals for $a_{1}, a_{0}$ and $y$ are given by:

$$
\begin{aligned}
& a_{1} \pm t_{\frac{1}{2} \alpha, n-2} \cdot \frac{S_{y / x}}{\sqrt{\sum\left(x_{i}-\bar{x}\right)^{2}}} \\
& a_{0} \pm t_{\frac{1}{2} \alpha, n-2} \cdot S_{y / x} \sqrt{\frac{1}{n}+\frac{\bar{x}^{2}}{\sum\left(x_{i}-x\right)^{2}}}
\end{aligned}
$$

and

$$
\begin{gathered}
\left(a_{0}+a_{1} \cdot x_{0}\right) \pm t_{\frac{1}{2} \alpha, n-2} \\
\cdot S_{y / x} \sqrt{\frac{1}{n} \frac{\left(x_{0}-\bar{x}\right)^{2}}{\sum\left(x_{i}-x\right)^{2}}} .
\end{gathered}
$$


The confidence interval determined for $y$ is that for its mean value calculated from a given $x$ value. Confidence intervals for the mean of the data for $1 \% \mathrm{Cr}-0.5 \% \mathrm{Mo}$ at 450 and $550^{\circ} \mathrm{C}$ and $\mathrm{SA} 508$ at $450^{\circ} \mathrm{C}$ and $0.5 \% \mathrm{Cr}-0.5 \% \mathrm{Mo}-0.25 \% \mathrm{~V}$ at $550^{\circ} \mathrm{C}$ were determined assuming Paris Law behaviour.

Figure 5 shows all the data for the five specimens of SA508 tested. In common with the other materials to follow, there is not a markedly linear trend to the data and the Paris Law fits only approximately. The two solid lines show the upper and lower $95 \%$ confidence intervals for the mean $\mathrm{d} a / \mathrm{d} N$ value as predicted by regression, assuming Paris Law behaviour.

Figures 6 to 8 show similar plots for the other alloys. Table 1 below lists some of the relevant statistical information including the number of specimens tested per type. The table also records the correlation coefficient, $r$, the number of specimens tested, $n$, and the central values of $C$ and $m$.

Table $1: 95 \%$ Confidence intervals for Paris Law coefficients.

\begin{tabular}{lccccccccc} 
ALLOY & ${ }^{\circ} \mathrm{C}$ & $C_{\text {low }}$ & $C_{\text {high }}$ & $C_{\text {avg. }}$ & $m_{\text {low }}$ & $m_{\text {high }}$ & $m_{\text {avg. }}$ & $r$ & $n$ \\
\hdashline$-1 C 508$ & 450 & $4.7 \mathrm{E}-14$ & $2.2 \mathrm{E}-12$ & $3.2 \mathrm{E}-13$ & 3.23 & 4.41 & 3.82 & 0.90 & 4 \\
SA50 & 450 & $2.1 \mathrm{E}-13$ & $3.4 \mathrm{E}-13$ & $8.5 \mathrm{E}-14$ & 3.95 & 4.80 & 4.38 & 0.92 & 5 \\
$1 \mathrm{Cr} 0.5 \mathrm{Mo}$ & 550 & $3.5 \mathrm{E}-11$ & $1.3 \mathrm{E}-10$ & $6.7 \mathrm{E}-11$ & 2.50 & 2.91 & 2.71 & 0.94 & 4 \\
$0.5 \mathrm{CrMoV}$ & 550 & $1.8 \mathrm{E}-13$ & $1.8 \mathrm{E}-12$ & $5.8 \mathrm{E}-13$ & 3.77 & 4.53 & 4.15 & 0.93 & 6
\end{tabular}

The approach above utilized the simplest model for fatigue crack growth data. It is however quite apparent that the fatigue crack growth curves are not linear and that a more realistic descriptive model, such as a model with a sigmoidal shape would be more useful. Accordingly the relevant coefficients for the sigmoidal model adopted were obtained by least square non-linear optimization and are listed below. Also calculated were the standard error of estimate of $y$ on $x$, $\mathrm{S}_{\mathrm{y} / \mathrm{x}}$, for each of the data sets. From the latter it is possible to construct approximate confidence intervals for each of the alloys and test conditions[25].

The sigmoidal model used was developed[26] using similar arguments to those originally adopted by Forman et al.[27] and is similar, although not identical, to the model proposed by Nicholson[28]. The model is:

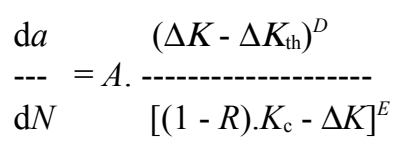

The relevant parameters for each of the test conditions are listed in Table 2. It should be obvious however, that the application of statistical regression techniques to the data can only yield estimates of the parameters $\Delta k_{\mathrm{th}}$ and $K_{\mathrm{c}}$. The accuracy of these estimates depends critically on the presence of data at the low and high extremes of crack growth rates. Since, in the present work, study of these extremes was not a major goal, such data is sparse. Thus the particular values of " $\Delta K_{\mathrm{th}}$ " and " $K_{\mathrm{c}}$ " presented must be seen more as statistical than as physical quantities. Nevertheless these two quantities are the statistically best estimates for their real physical counterparts, in terms of the model, that each set of data allows.

Table 2 : Parameters for the sigmoidal crack growth model.

\begin{tabular}{lllccccc} 
ALLOY & ${ }^{\circ} \mathrm{C}$ & $\mathrm{A}$ & $" \Delta K_{\mathrm{th}} "$ & $" K_{\mathrm{c}} "$ & $D$ & $E$ & $\log _{\mathrm{e}}\left(S_{y / x}\right)$ \\
\hdashline $\mathrm{SA508}$ & 450 & $3.596 \mathrm{E}-2$ & 11.2 & 199 & 1.726 & 3.490 & 0.427 \\
$1 \mathrm{Cr} 0.5 \mathrm{Mo}$ & 450 & $3.060 \mathrm{E}-3$ & 16.3 & 109 & 1.125 & 2.93 & 0.351 \\
$1 \mathrm{Cr} 0.5 \mathrm{Mo}$ & 550 & $1.035 \mathrm{E}-2$ & 14.4 & 92 & 0.602 & 2.85 & 0.257 \\
$0.5 \mathrm{CrMoV}$ & 550 & $3.82 \mathrm{E}-3$ & 10.4 & 111 & 1.297 & 2.949 & 0.461
\end{tabular}

The four sets of data are plotted in Figures 9 to 12. 


\section{Growth rates}

Figure 13 shows the $1 \mathrm{~Hz}$ fatigue test data of three sets of workers for conditions around $550^{\circ} \mathrm{C}$ as well as the scatterband of crack propagation results for the $1 \% \mathrm{Cr}-0.5 \% \mathrm{Mo}$ measured in the present work. The experimental details pertaining to these data sets are given in Table 3 below.

Table 3 : Testing different materials at $550^{\circ} \mathrm{C}$.

\begin{tabular}{lllcc} 
AUTHOR & MATERIAL & FREQUENCY & TEMPERATURE & APPROX. $m$ \\
\hline Corwin[29] & $2.25 \% \mathrm{Cr}-1 \% \mathrm{Mo}$ & $1 \mathrm{~Hz}$ & $550^{\circ} \mathrm{C}$ & 3.5 \\
Saxena[30] & $0.3 \% \mathrm{C}-1.2 \% \mathrm{Cr}-0.25 \% \mathrm{~V}$ & $1 \mathrm{~Hz}$ & $538^{\circ} \mathrm{C}$ & 2.2 \\
Haigh[31] & $1 \% \mathrm{Cr}-1 \% \mathrm{Mo}-0.25 \% \mathrm{~V}$ & $1 \mathrm{~Hz}$ & $550^{\circ} \mathrm{C}$ & 1.8
\end{tabular}

The Paris lines and differing ' $m$ ' values in Figure 13 for these different materials appear to show that they have different rates of fatigue crack propagation. However, examination of the scatter band for $1 \% \mathrm{Cr}-0.5 \% \mathrm{Mo}$ obtained in the present work shows that the range of $\Delta K$ values over which an elevated temperature fatigue test is run will have a dramatic effect on the resultant ' $m$ '. Thus tests conducted strictly over the mid-range of Stage II crack growth will have far lower ' $m$ 's than those which include data at either low or high values of $\Delta K$.

These limitations should be kept in mind when examining Figure 14 which compares the 95\% confidence intervals for Paris Law-type crack growth for the four major test/alloy conditions. In this case use of the Paris Law and conventional correlation theory appears to show that the alloys have resolvably different fatigue crack growth behaviour.

Figures 15 and 16 show the net result of fitting the sigmoidal model to each of the four main data sets. In the case of $1 \% \mathrm{Cr}-0.5 \% \mathrm{Mo}$ and SA508 at $450 \mathrm{oC}$ there is only a slight suggestion that the fatigue crack growth behaviour might be different. Indeed examination of the original data for SA508 (Figure 5) shows that the curve has been pulled down by the data from a single test and if that test were ignored then the behaviour for these two alloys would be even more alike. In the case of $1 \% \mathrm{Cr}-0.5 \% \mathrm{Mo}$ and $0.5 \% \mathrm{Cr}-0.5 \% \mathrm{Mo}-0.25 \% \mathrm{~V}$ at $550^{\circ} \mathrm{C}$ the data for the $1 \% \mathrm{Cr}-0.5 \% \mathrm{Mo}$ lies completely within the scatter band for the data for the $0.5 \% \mathrm{Cr}-0.5 \% \mathrm{Mo}-0.25 \% \mathrm{~V}$ alloy. On the basis of the statistical treatment described, there seems to be no difference between the $1 \mathrm{~Hz}$ fatigue crack growth behaviour of these two alloys.

\section{CONCLUSIONS}

1. A sigmoidal model for crack growth is more accurate than the Paris model and allows more meaningful comparisons to be made.

2. There does not seem to be a very great difference between the fatigue crack growth rates of $1 \% \mathrm{Cr}-0.5 \% \mathrm{Mo}$ and $\mathrm{SA} 508$ at $450^{\circ} \mathrm{C}, 1 \mathrm{~Hz}$ and $R=0.1$.

3. There is no significant difference between the fatigue crack growth behaviour of $1 \% \mathrm{Cr}-0.5 \% \mathrm{Mo}$ and $0.5 \% \mathrm{Cr}$ $0.5 \% \mathrm{Mo}-0.25 \% \mathrm{~V}$ at $550^{\circ} \mathrm{C}, 1 \mathrm{~Hz}$ and $R=0.1$. In addition the growth rates determined for these two materials under these conditions seems identical to that reported previously in the literature for $2.25 \% \mathrm{Cr}-1 \% \mathrm{Mo}, 0.3 \% \mathrm{C}-1.2 \% \mathrm{Cr}-0.25 \% \mathrm{~V}$ and $1 \% \mathrm{Cr}-1 \% \mathrm{Mo}-0.25 \% \mathrm{~V}$.

4. Fatigue at $1 \mathrm{~Hz}, R=0.1$ for these alloys proceeded at both temperatures by the striation-forming mechanism of alternating crack tip blunting and resharpening.

\section{Acknowledgement}

This paper is published by permission of the Council for Mineral Technology (Mintek).

\section{REFERENCES}

[1] L.P. Pook, "The role of crack growth in metal fatigue", The Metals Society, London (1983).

[2] R.W. Hertzberg, "Deformation and fracture mechanics of engineering materials", John Wiley \& Sons (1976). 
[3] S.T. Rolfe and J.M. Barsom, "Fracture and fatigue control in structures", Prentice-Hall (1977)

[4] C.R. Aita and J. Weertman, "The effect of microstructure on fatigue crack propagation in iron-carbon alloys", Met. Trans. A, 10, 535-544, (1979).

[5] J.P. Benson and D.V. Edmonds, "Effect of microstructure on fatigue in the threshold region of low-alloy steel", Metal Science May 1978, 223-232 (1978).

[6] T. Tshihara and Y. Kowata, "The influences of dual phase microstructures on crack propagation by mean stress", in Fracture Mechanics Technology Applied to Material Evaluation and Structure Design, G.C. Sih, N.E. Ryans and R. Jones (Eds.), Martinus Nijhoff Publishers, The Hague, Netherlands, 109-120 (1983).

[7] M. Suzuki and A.J. McEvily, "Microstructural effect on fatigue crack growth in a low carbon steel", Met. Trans. A, $10,475-* * *,(1979)$.

[8] C. Poon, D. Vitale, M. Singh and D. Hoeppner, "Fatigue crack propagation behaviour of rotor and wheel materials used in steam turbines", Int. J. Fatigue 5(2), 87-93 (1983).

[9] H. Ishii, T. Kawarzaki and Y. Fujimura, "Fatigue in binary alloys of bcc iron", Met. Trans. A 15, 679-691 (1984).

[10] R.P. Skelton and K.D. Challenger, "Fatigue crack growth in $21 / 4 \mathrm{Cr}-1 \mathrm{Mo}$ steel at $525^{\circ} \mathrm{C}$. II. Prediction of continuous cycling endurances", Mat. Sci. \& Eng. 65, 283-288 (1984).

[11] C.R. Brinkman, "High-temperature time-dependent fatigue behaviour of several engineering structural alloys", Int. Metal Reviews 30(5), 235-258 (1985).

[12] R.P. Skelton, "Crack growth during high strain fatigue of 0.5Cr-Mo-V steel at 825K", Mat. Sci. \& Eng. 32, 211219 (1978).

[13] G.A.Webster, "High temperature fatigue crack growth in superalloy blade materials", Mater. Sci. Technol. 3, 716725, (1987).

[14] K.H. Schwalbe and D. Hellman, "Application of the electrical potential method to crack length measurements using Johnson's formula", J. of Testing \& Evaluation 9(3),218-221 (1981).

[15] M.B. Cortie "On fatigue crack propagation and its analysis, with particular reference to high temperature fatigue in low alloy steels", PhD Thesis, University of the Witwatersrand, South Africa (1987).

[16] P. Paris and F. Erdogan, "A critical analysis of crack propagation laws", Trans. of the ASME J. of Basic Eng. December 1963, 528-534 (1963).

[17] G.O. Johnston, "Statistical scatter in fracture toughness and fatigue crack growth rate data" in Probabilistic Fracture Mechanics and Fatigue Methods, J.M .Bloom and J.C. Ekvall (Eds.), ASTM STP 798, 42-66 (1983).

[18] J.P. Hickerson and R.W. Hertzberg, "The role of mechanical properties in low stress fatigue crack propagation", Met. Trans. 3, 179-189 (1972).

[19] E.H. Niccolls, "A correlation for fatigue crack growth rate", Scripta Met. 10, 295-298 (1976).

[20] K. Tanaka and S. Matsuoka, "A tentative explanation for two parameters, $C$ and $m$, in Paris equation of fatigue crack growth", Int. J. Fract. 13(5), 563-583, (1977).

[21] M.B. Cortie and G.G. Garrett, "On the correlation between the $C$ and $m$ in the Paris equation for fatigue crack propagation", to be published in Engineering Fracture Mechanics.

[22] D.F. Ostergaard and B.M. Hillberry, "A characterization of the variability in fatigue crack propagation data" in Probabilistic Fracture Mechanics and Fatigue Methods, J.M.Bloom and J.C.Ekvall (eds.), ASTM STP 798, 97-115 (1983).

[23] W.G. Clarke and S.J. Hudak, "Variability in fatigue crack growth rate testing", J of Testing \& Evaluation 3(6),454476 (1975). 
[24] ASTM E647-86, "Standard test method for constant-load- amplitude fatigue crack growth rates above 10ü8 m/cycle", ASTM (1986).

[25] M.R. Spiegel, "Theory and problems of statistics", Schaum's Outline Series, McGraw-Hill 1972.

[26] M.B. Cortie and G.G. Garrett, "Synergistic interactions between creep and environment in 'creep-fatigue'", in Creep and Fracture of Engineering Materials and Structures, B. Wilshire and R.W. Evans (eds.), The Institute of Metals, London, 635-648 (1987).

[27] R.G. Forman, V.E. Kearney and R.M. Engle, "Numerical analysis of crack propagation in cyclic loaded structures", Trans. of the ASME, J. of Basic Eng. Sept 1967, 459-464 (1967).

[28] C.E. Nicholson, "Influence of mean stress and environment on crack growth", Conference of Mechanics and Mechanisms of Crack Growth, Cambridge, England, 226-233 (1973).

[29] W.R. Corwin, M.K. Booker, B.L.P. Booker and C.R. Brinkman, "Characterizing fatigue crack propagation in 2 1/4Cr-1Mo steel for steam generator applications" Oak Ridge National Laboratory report, undated.

[30] A. Saxena, "A model for predicting the effect of frequency on fatigue crack growth behaviour at elevated temperature", Fat. of Eng. Mat. \& Struc., 3, 247-255 (1981).

[31] J.R. Haigh, R.P. Skelton and C.E. Richards, "Oxidation- assisted crack growth during high cycle fatigue of a $1 \%$ Cr- Mo-V steel at 550 ${ }^{\circ}$ ", Mat. Sci. \& Eng., 26,167-174 (1976). 
PANER 9916 , CORTIE

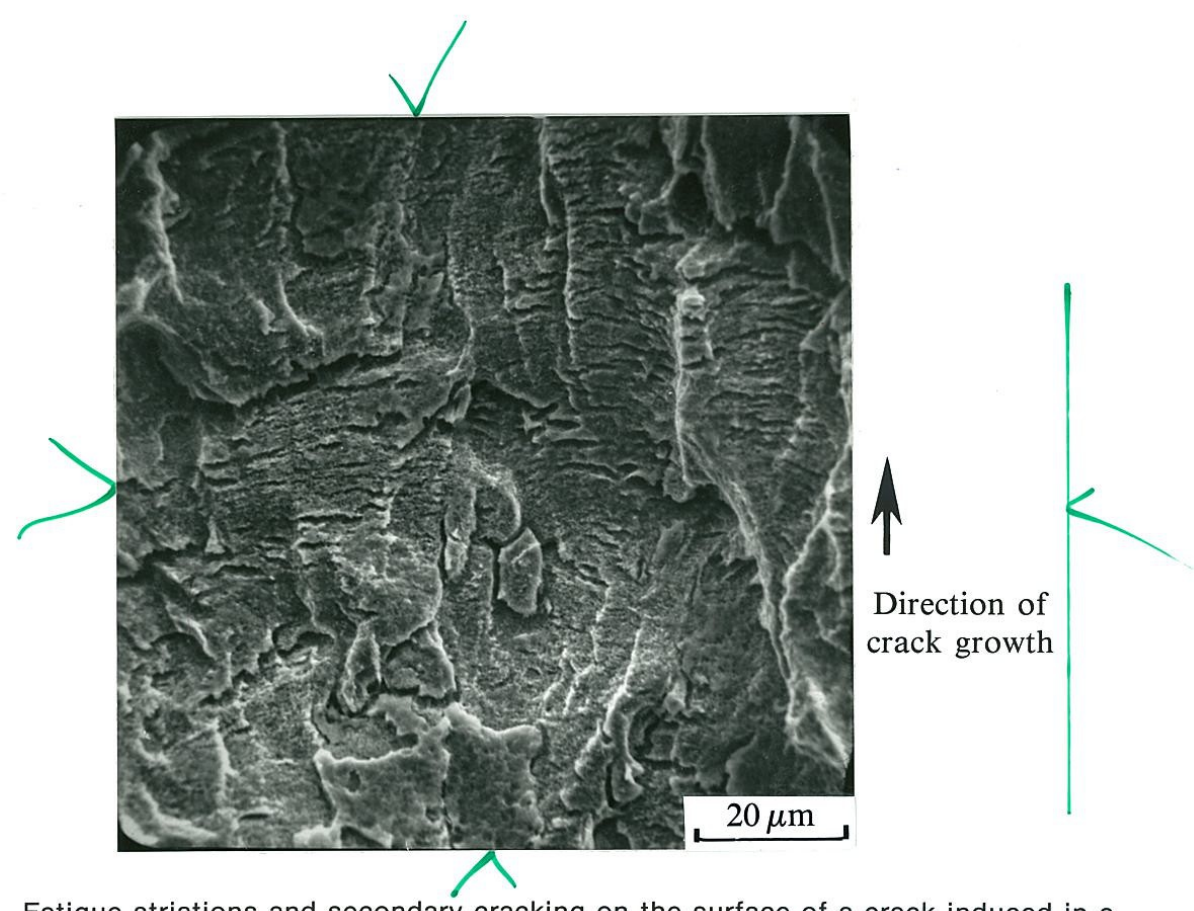

FIGURE 1. Fatigue striations and secondary cracking on the surface of a crack induced in a specimen of SA508 steel tested at $450^{\circ} \mathrm{C}$ and $1 \mathrm{~Hz}$

\section{TAFMEC 252 \&}

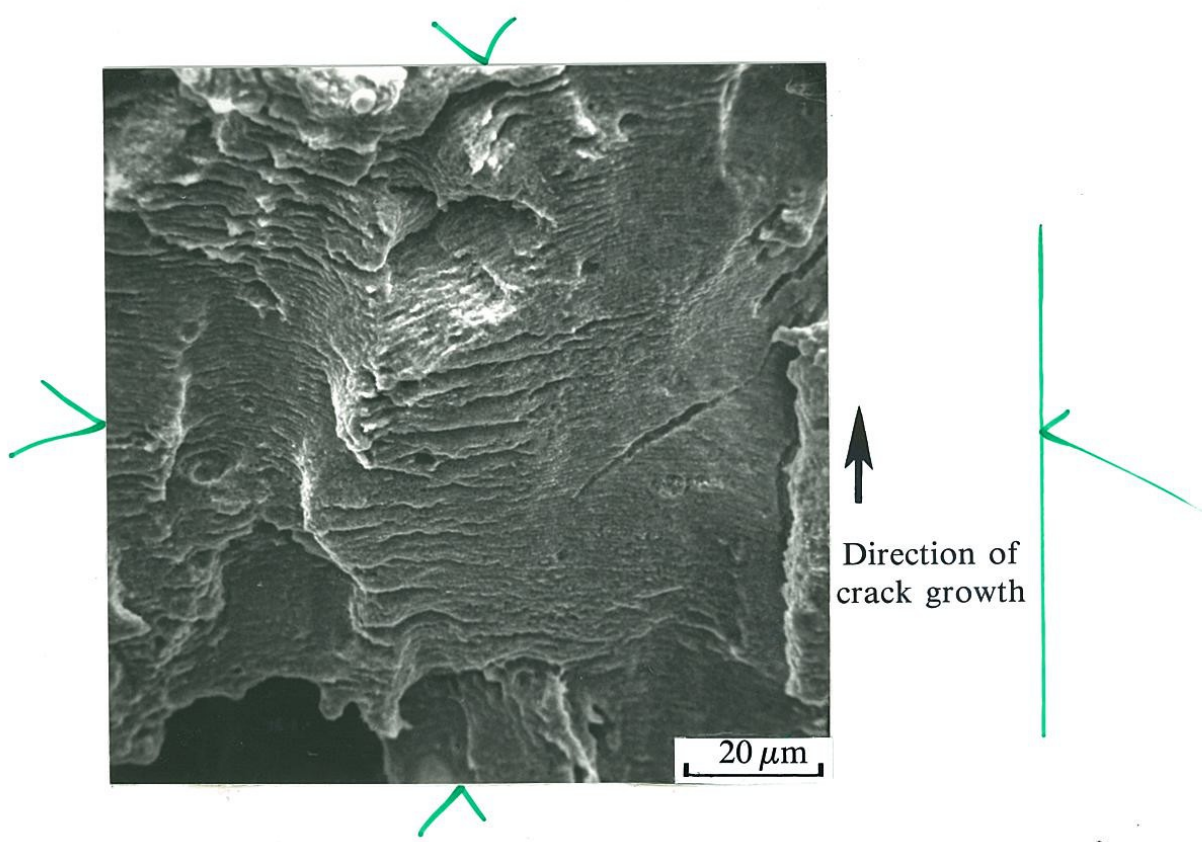

FIGURE 2. Coarse fatigue striations on the surface of a crack induced in a specimen of $\mathrm{Fe}-1 \%$ $\mathrm{Cr}-0.5 \%$ Mo tested at $450^{\circ} \mathrm{C}$ and $1 \mathrm{~Hz}$ 


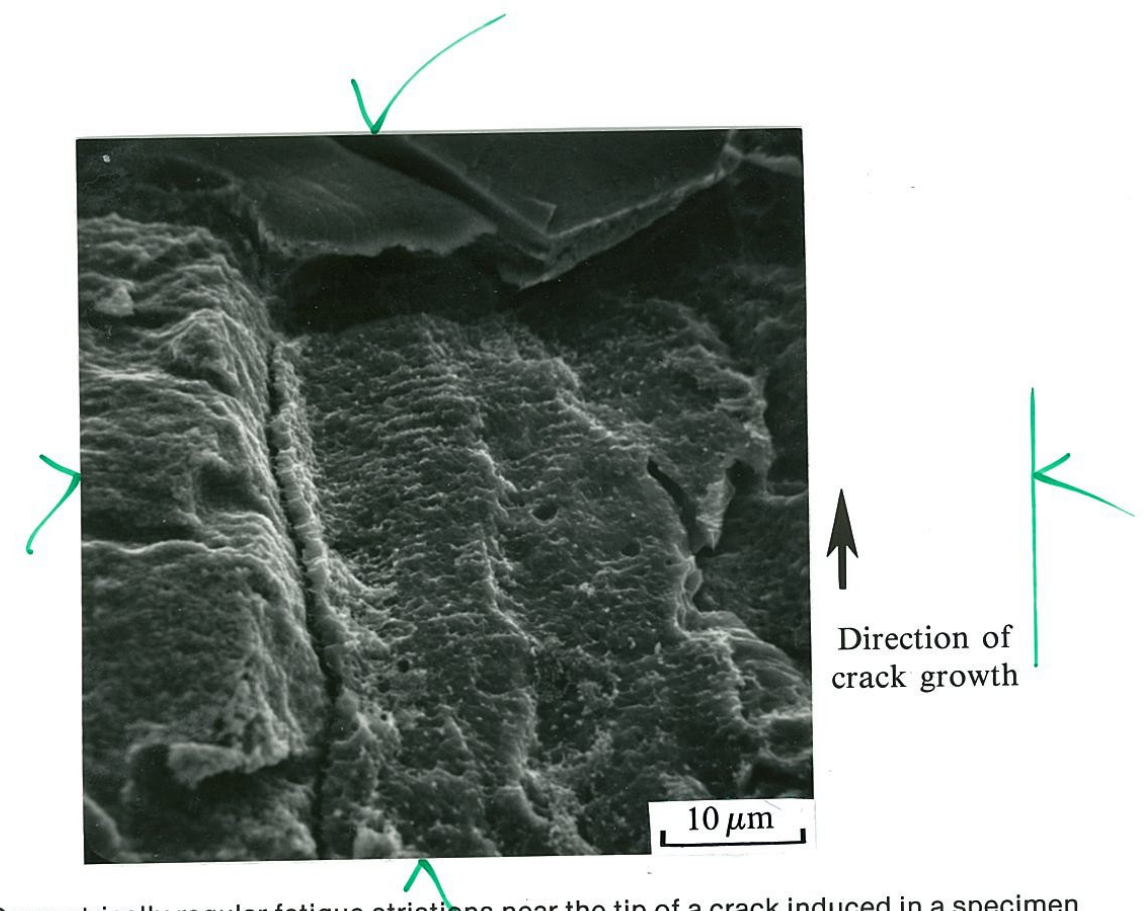

FIGURE 3. Geometrically regular fatigue striations near the tip of a crack induced in a specimen of $\mathrm{Fe}-1 \% \mathrm{Cr}-0.5 \%$ Mo tested at $550^{\circ} \mathrm{C}$ and $1 \mathrm{~Hz}$

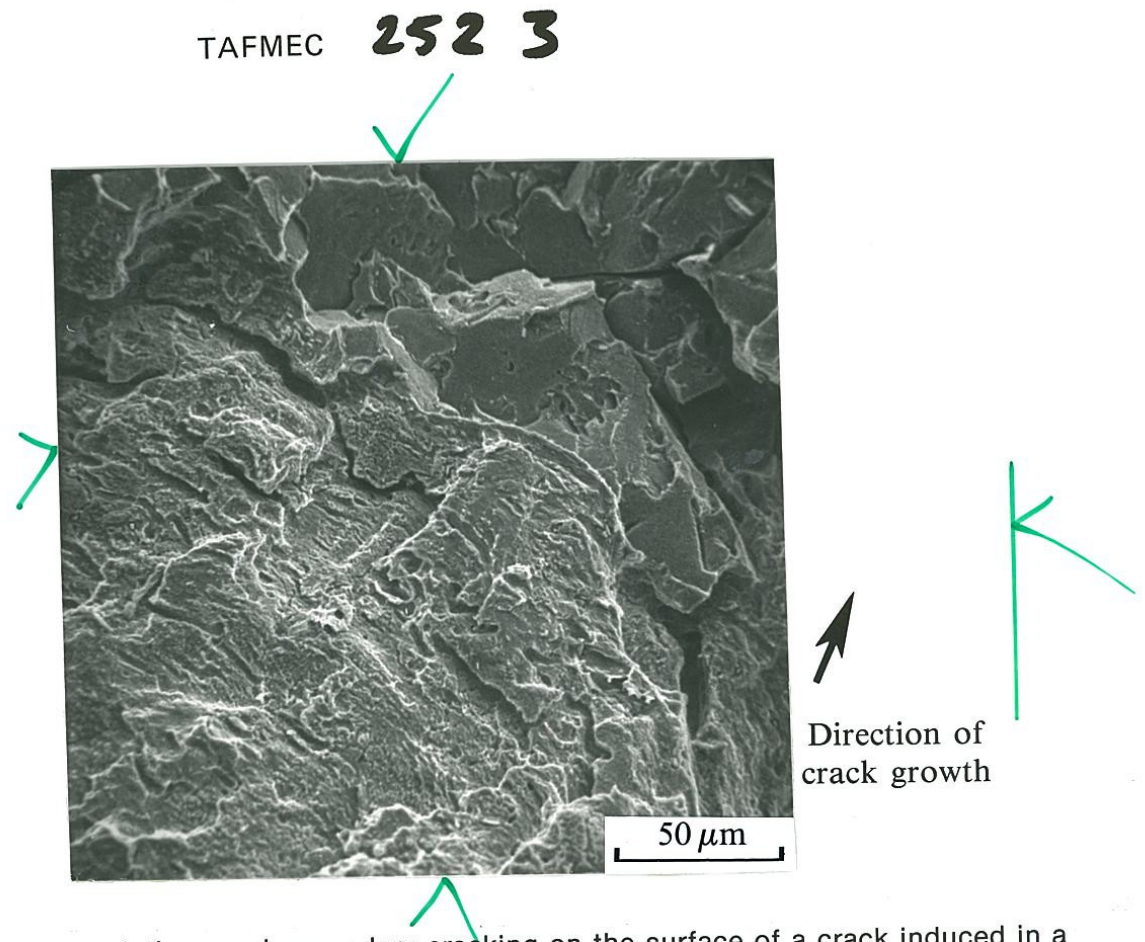

FIGURE 4. Fatigue striations and secondary cracking on the surface of a crack induced in a specimen of $\mathrm{Fe}-0.5 \% \mathrm{Cr}-0.5 \% \mathrm{Mo}-0.25 \% \mathrm{~V}$ steel tested at $550^{\circ} \mathrm{C}$ and $1 \mathrm{~Hz}$. (The brittle cle
at top right was produced when the specimen was broken open for examination) 


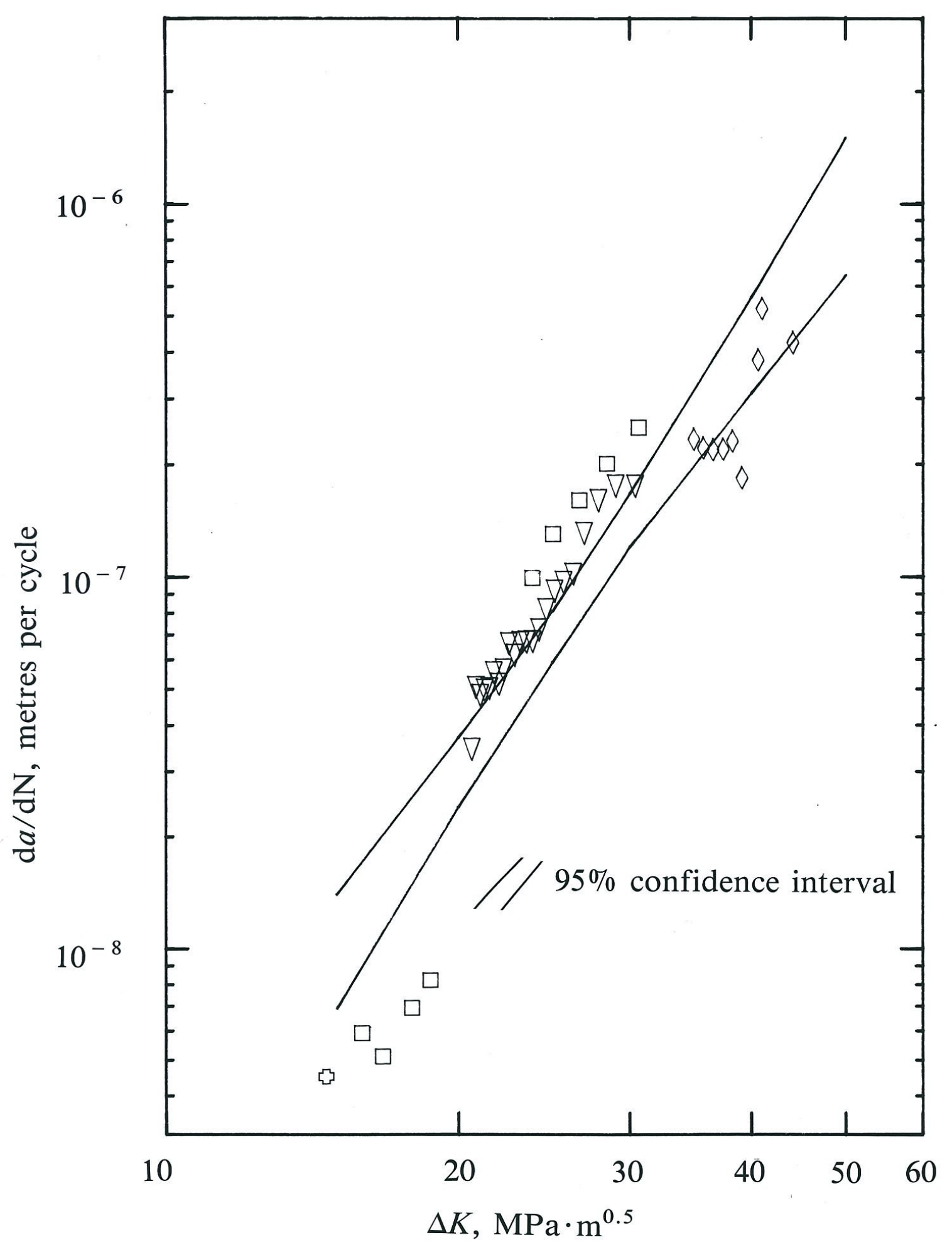

FIGURE 5. Description of fatigue-crack growth in SA508 at $450^{\circ} \mathrm{C}$ and $1 \mathrm{~Hz}$ assuming Paris Law TAFMEC 2825 behaviour 


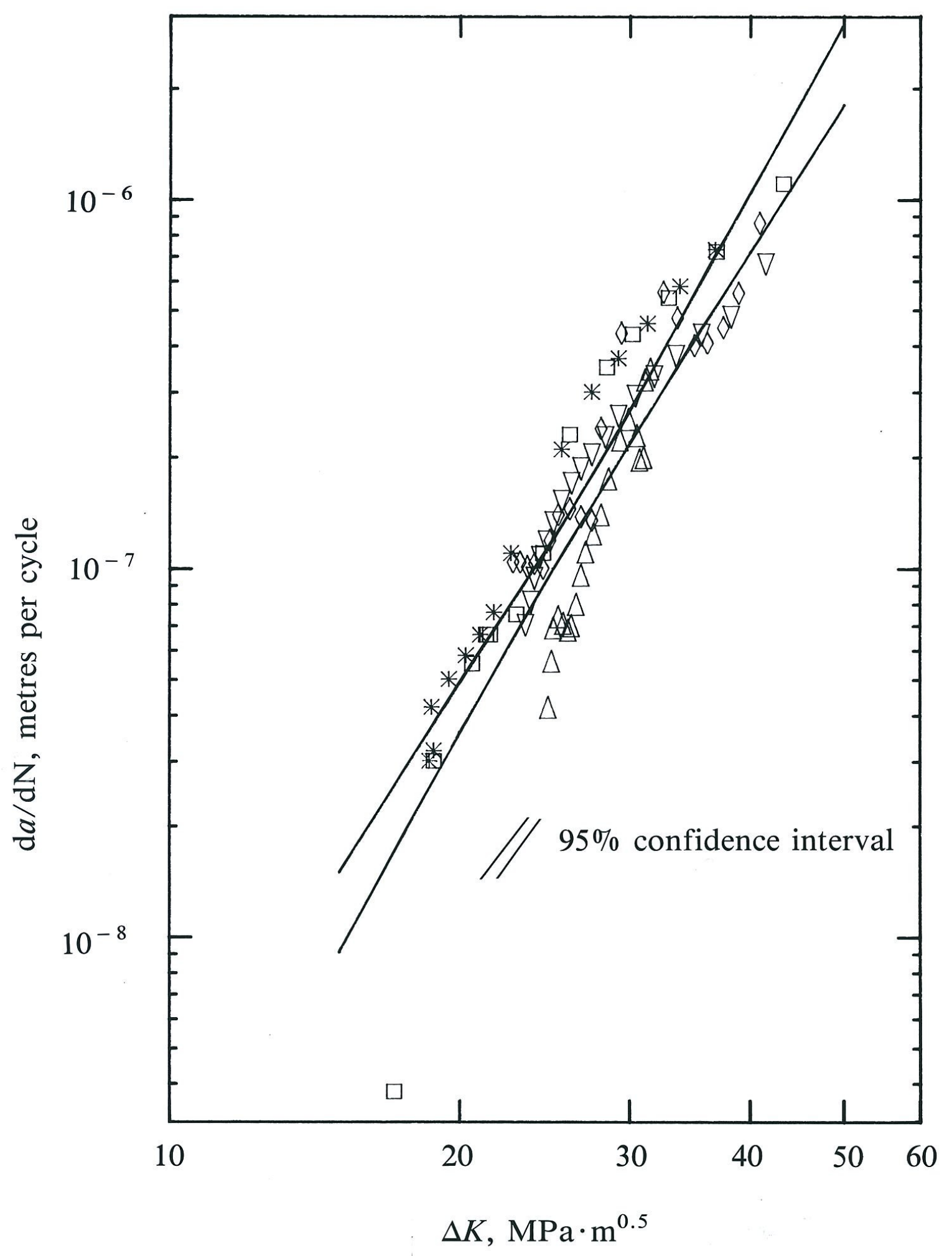

FIGURE 6. Description of fatigue-crack growth in $\mathrm{Fe}-1 \% \mathrm{Cr}-0.5 \% \mathrm{Mo}$ at $450^{\circ} \mathrm{C}$ and $1 \mathrm{~Hz}$ assuming Paris Law behaviour 


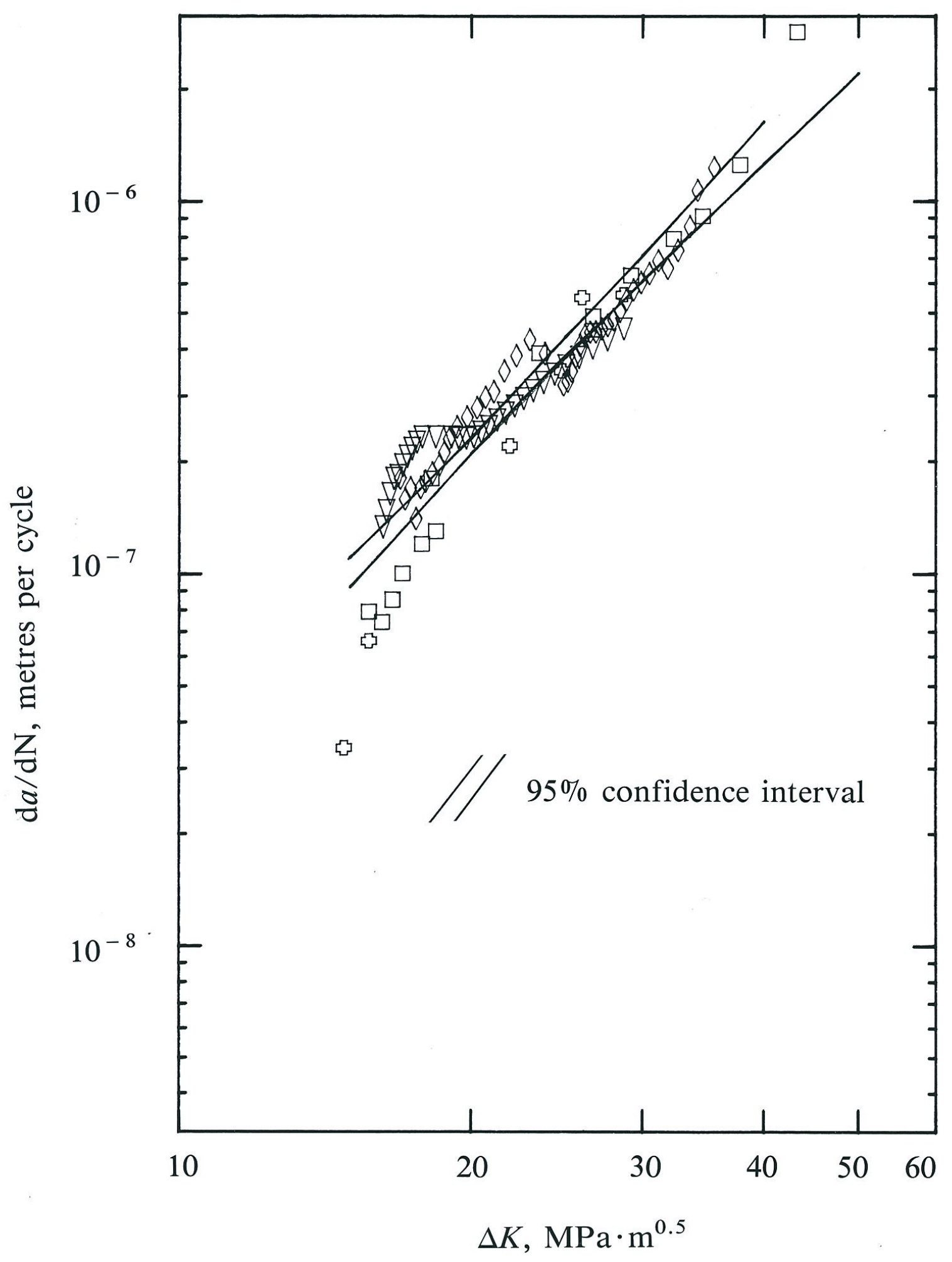

FIGURE 7. Description of fatigue-crack growth in $\mathrm{Fe}-1 \% \mathrm{Cr}-0.5 \% \mathrm{Mo}$ at $550^{\circ} \mathrm{C}$ and $1 \mathrm{~Hz}$ assuming Paris Law behaviour FAFMEC 2527 


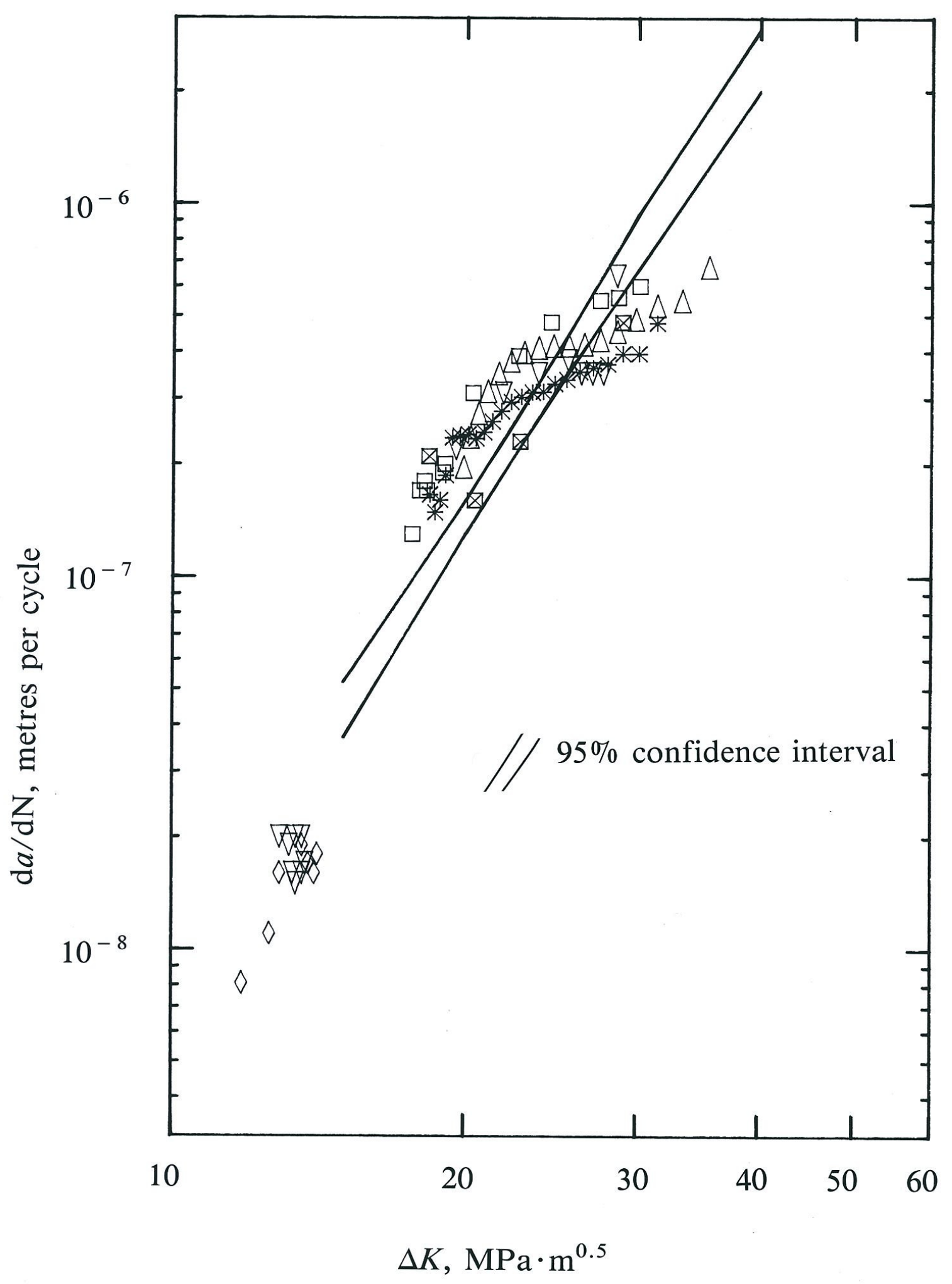

FIGURE 8. Description of fatigue-crack growth in Fe-0.5\% Cr- $0.5 \% \mathrm{Mo}-0.25 \% \mathrm{~V}$ at $550{ }^{\circ} \mathrm{C}$ and TAFMEC $252 \& 1 \mathrm{~Hz}$ assuming Paris Law behaviour 


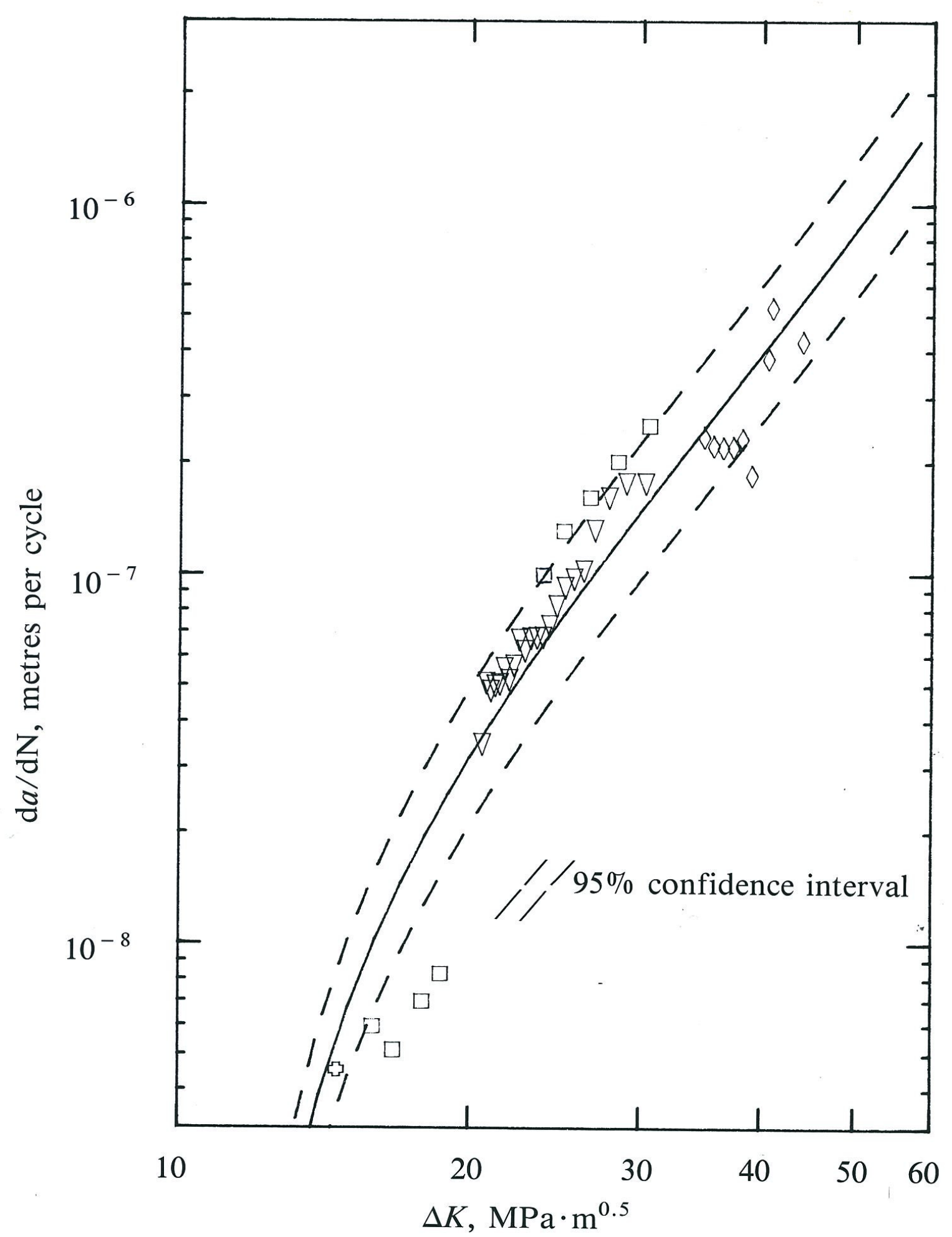

FIGURE 9. Description of fatigue-crack growth in SA508 at $450^{\circ} \mathrm{C}$ and $1 \mathrm{~Hz}$ assuming sigmoidalTAFMEC 2529 law behaviour 


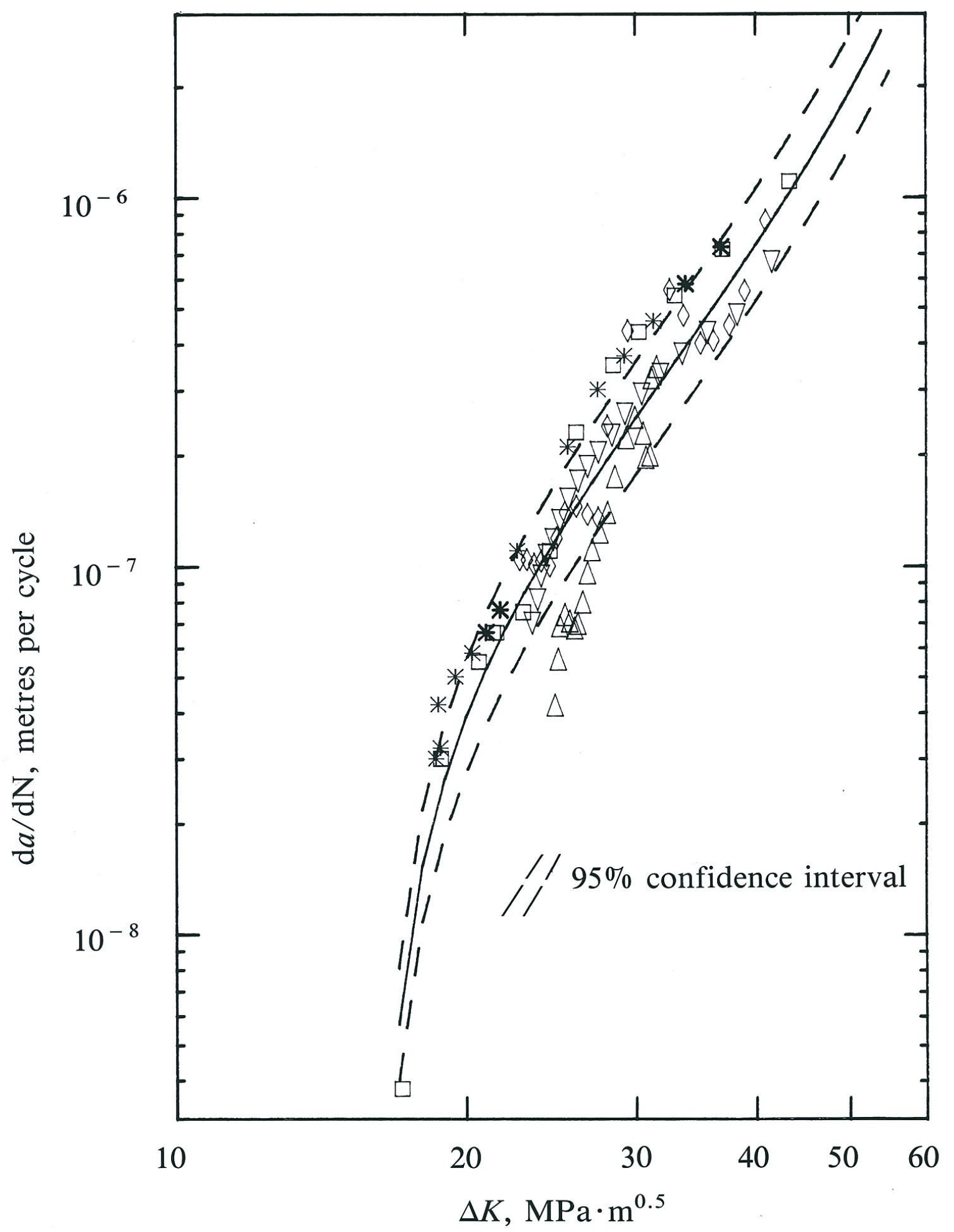

FIGURE 10. Description of fatigue-crack growth in $\mathrm{Fe}-1 \% \mathrm{Cr}-0.5 \%$ Mo at $450{ }^{\circ} \mathrm{C}$ and $1 \mathrm{~Hz}$ TAFMEC 95210 assuming sigmoidal-law behaviour 


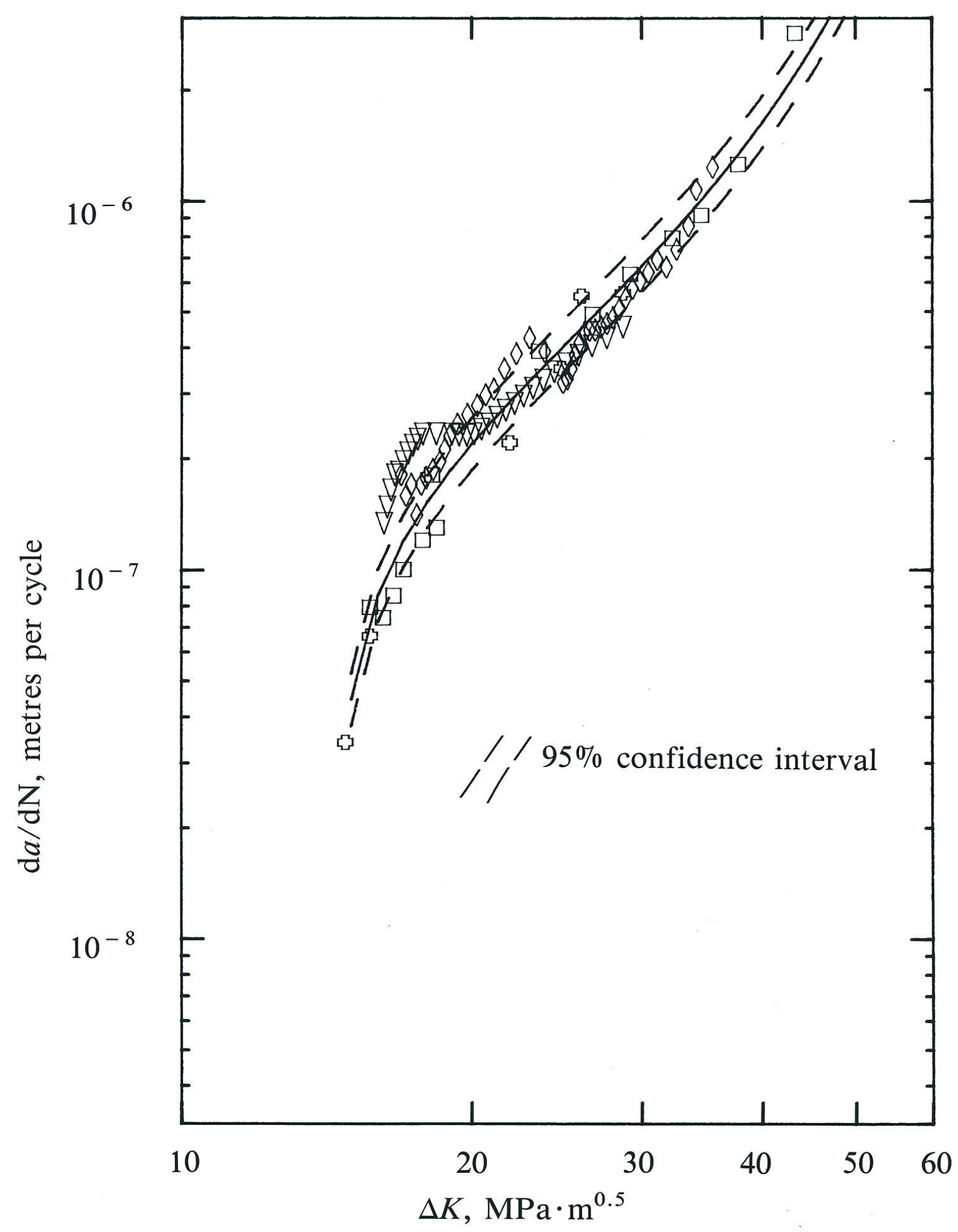

FIGURE 11. Description of fatigue-crack growth in $\mathrm{Fe}-1 \% \mathrm{Cr}-0.5 \% \mathrm{Mo}$ at $550{ }^{\circ} \mathrm{C}$ and $1 \mathrm{~Hz}$ TAFMEC 252 \& assuming sigmoidal-law behaviour 


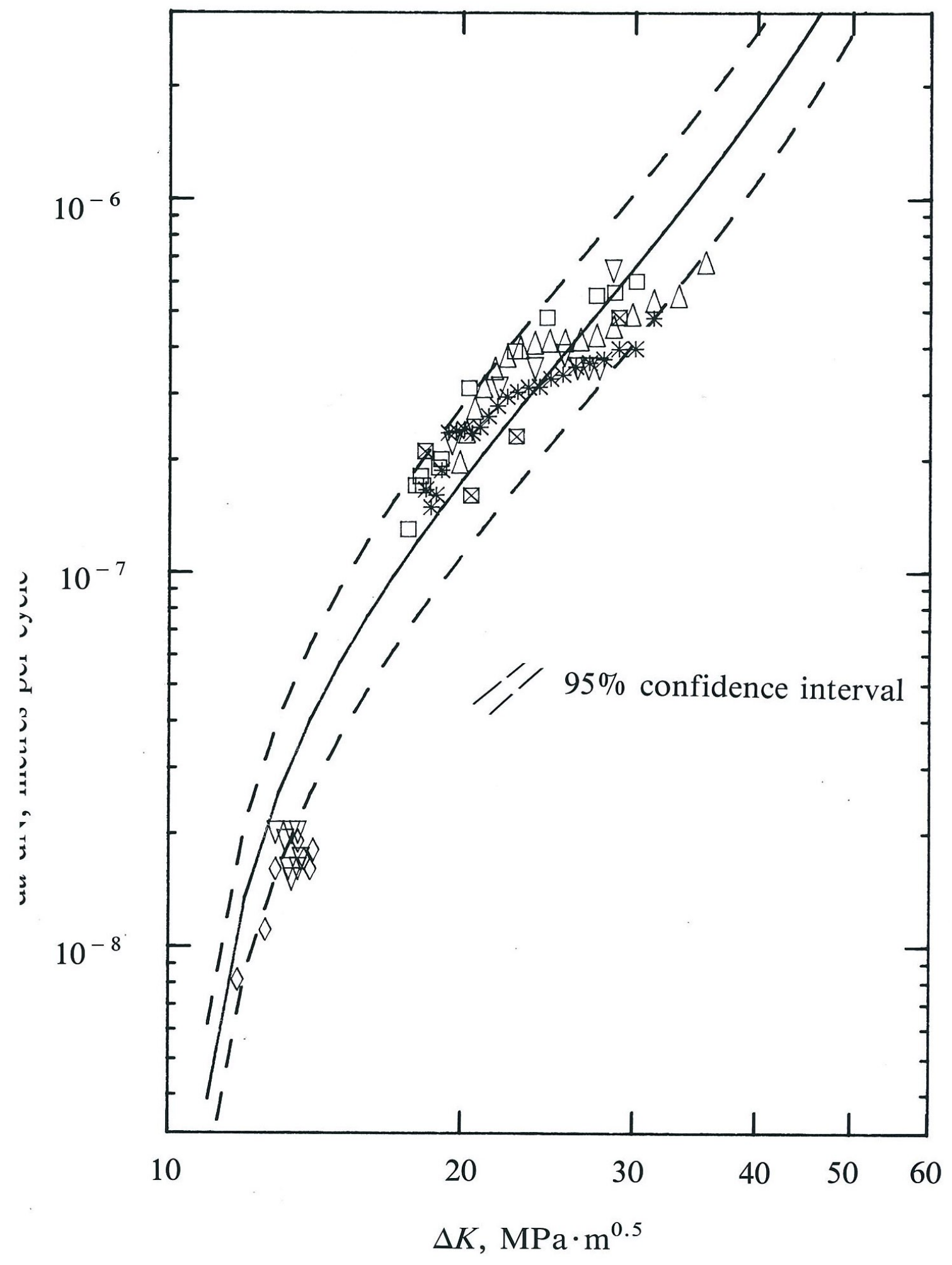

FIGURE 12. Description of fatigue-crack growth in $\mathrm{Fe}-0.5 \% \mathrm{Cr}-0.5 \% \mathrm{Mo}-0.25 \% \mathrm{~V}$ at $550{ }^{\circ} \mathrm{C}$ and TAFMEC 23812 1 $1 \mathrm{~Hz}$ assuming sigmoidal-law behaviour 


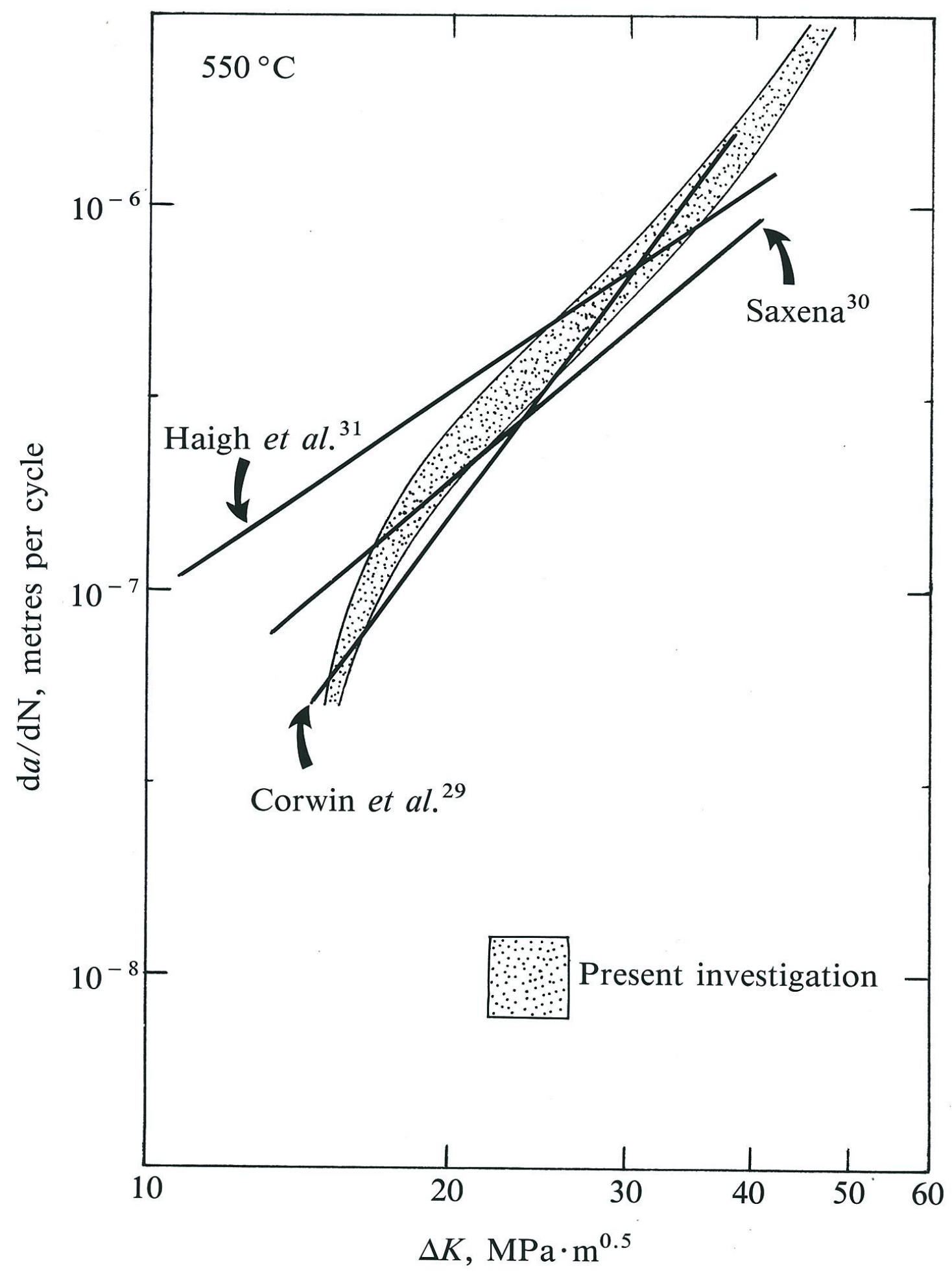

TAFMEC RIGUR 13. Comparison of the fatigue-crack growth rates of four alloys at $550^{\circ} \mathrm{C}$ and $1 \mathrm{~Hz} ?$ 


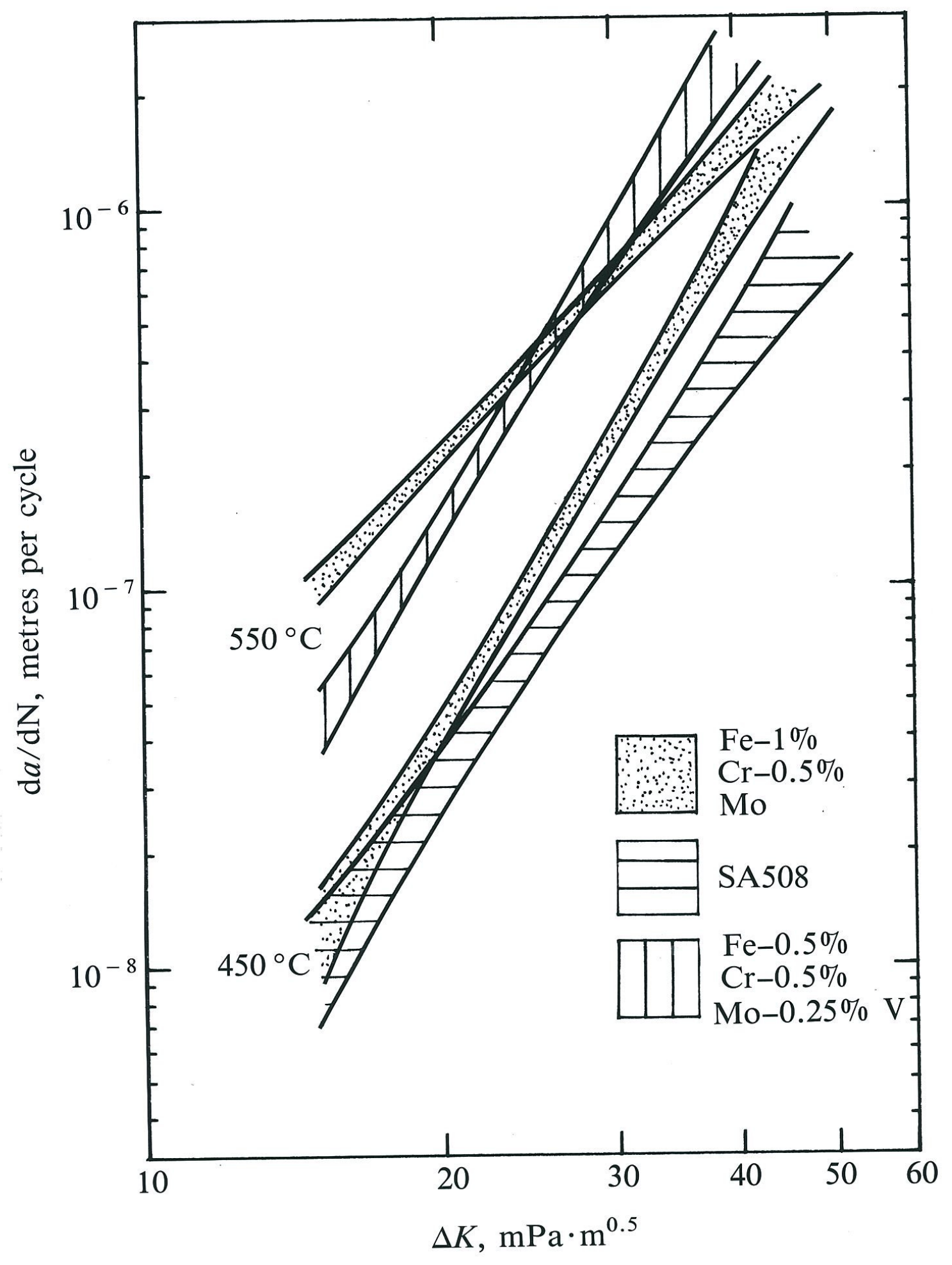

FIGURE 14. $95 \%$ per cent confidence intervals for fatigue-crack growth rates in the three alloys, TAFMEC 25214 assuming Paris Law behaviour 


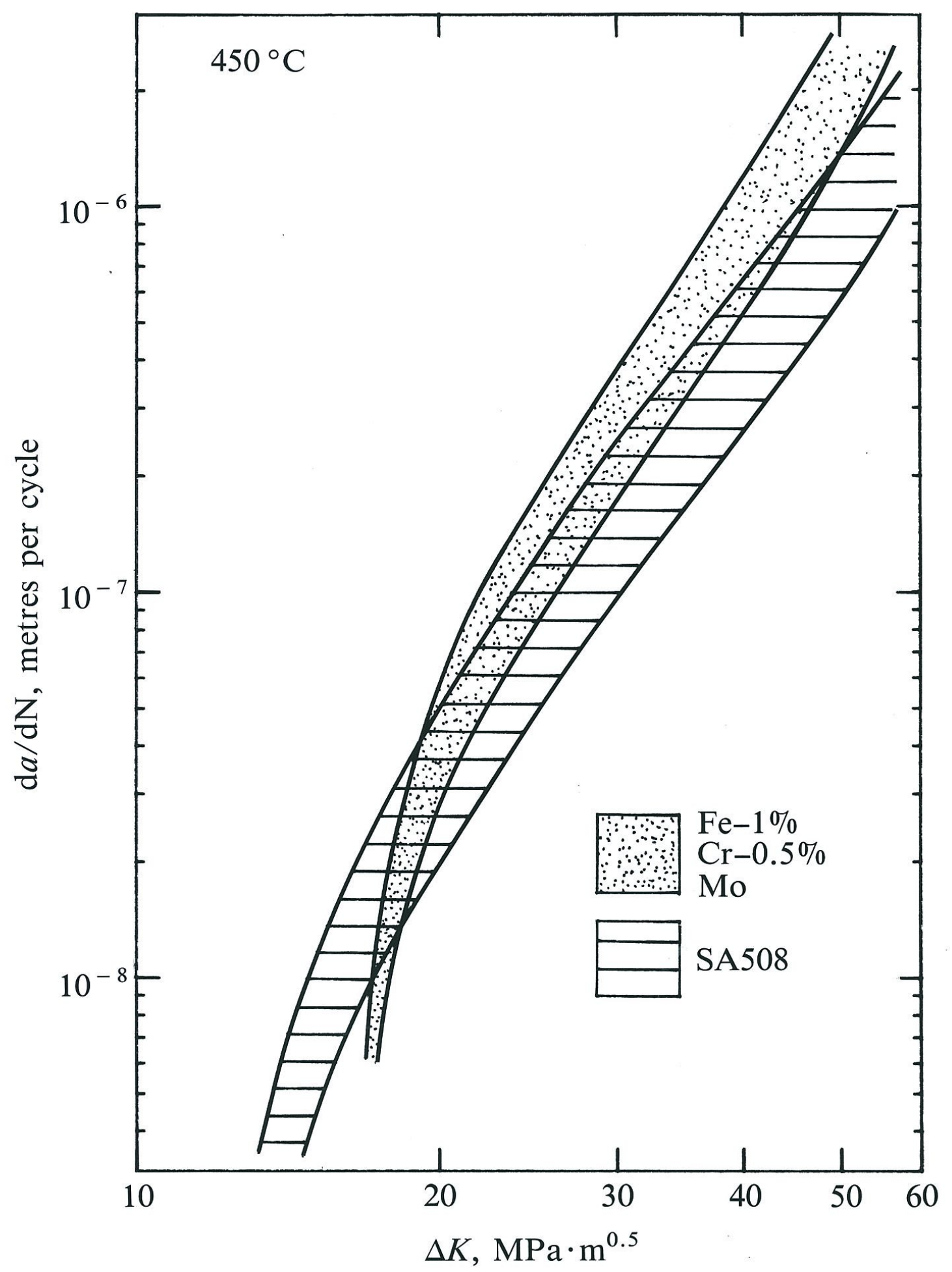

FIGURE 15. Comparison of the 95 per cent confidence intervals for fatigue-crack growth rates

TAFMEC $25215^{\text {in }}$ 


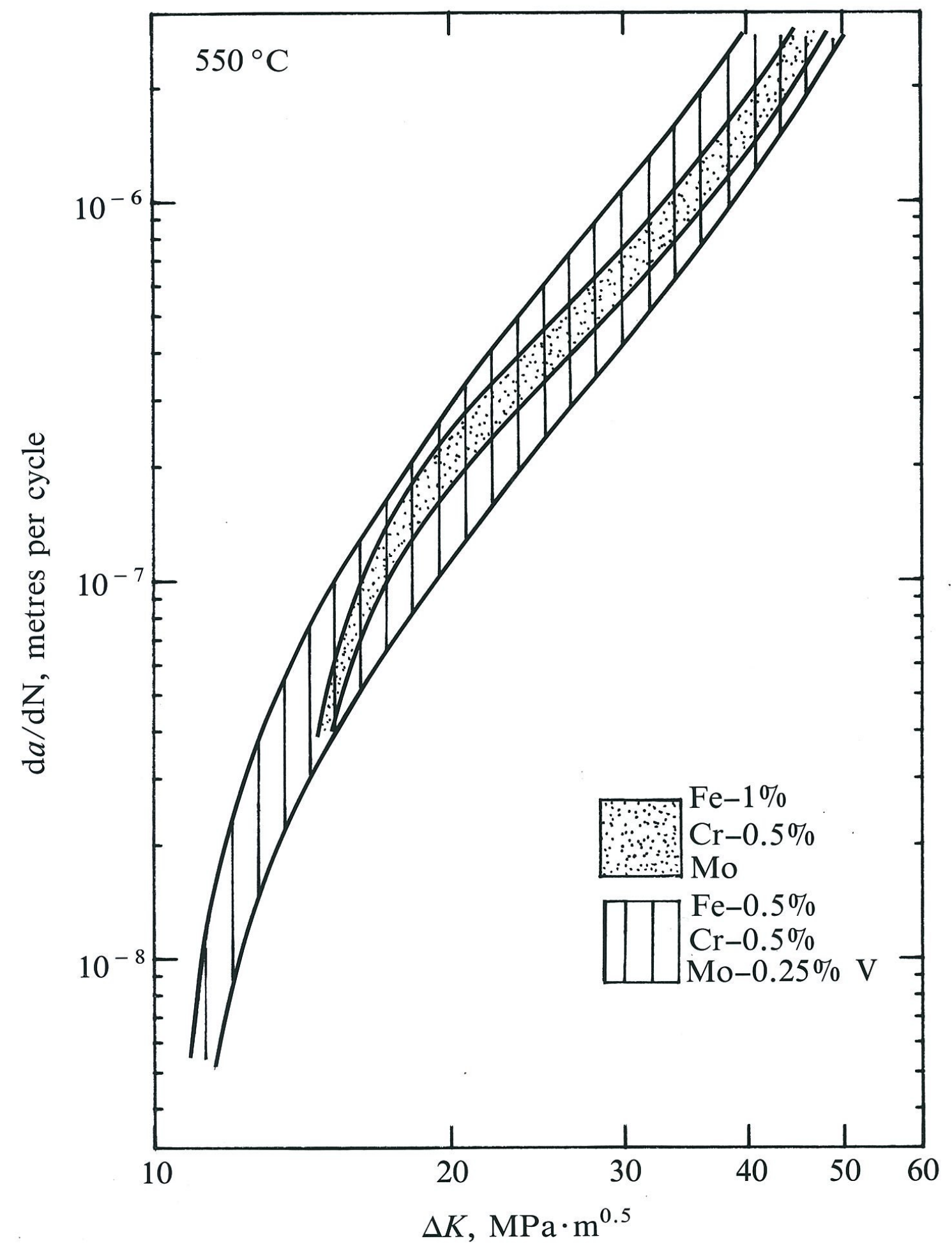

FIGURE 16. Comparison of the 95 per cent confidence intervals for fatigue-crack growth rates 25216 in two alloys at $550^{\circ} \mathrm{C}$ assumng sigmoidal-law behaviour 